\title{
Assessment of vitamin D status and parathyroid hormone during a combined intervention for the treatment of childhood obesity
}

\author{
Teodoro Durá-Travé $\mathbb{D}^{1,2,3}$, Fidel Gallinas-Victoriano ${ }^{2}$, María Jesús Chueca-Guindulain ${ }^{2,3}$, Sara Berrade-Zubiri ${ }^{2,3}$, \\ María Urretavizcaya-Martinez ${ }^{2}$ and Lotfi Ahmed-Mohamed ${ }^{2}$
}

\begin{abstract}
Background: Obesity is associated with vitamin D deficiency. The aim of this work is to analyze the changes in vitamin D status and PTH levels in a group of children with obesity receiving combined intervention program in order to get BMl status reduction.

Methods: Longitudinal study in 119 children with obesity, aged 9.1-13.9 years, included in a 1-year combined dietarybehavioral-physical activity intervention. Anthropometric measurements (weight, height, BMI and fat mass index) were registered every 3 months and blood testing (calcium, phosphorous, 25(OH)D and PTH) were collected at the beginning and after 12 months of follow-up. A control group was recruited (300 healthy children, aged 8.1-13.9 years). The criteria of the US Endocrine Society were used for the definition of hypovitaminosis D.

Results: Vitamin D deficiency was significantly higher in obesity group (31.1 vs. 14\%). There was negative correlation between $25(\mathrm{OH}) \mathrm{D}$ and fat mass index $(r=-0.361, p=0.001)$. Patients with BMl reduction throughout combined intervention were 52 (43.7\%). There was a significant increase in the prevalence of hypovitaminosis $D$ in patients without BMI reduction at the end of follow-up, but in those patients with BMI reduction there was no changes of vitamin D status.
\end{abstract}

Conclusions: Obesity increases the prevalence of suboptimal vitamin D status, and a BMI status reduction in children with obesity may be required to at least stabilize vitamin $\mathrm{D}$ status.

\section{Introduction}

Obesity is associated with vitamin D deficiency ${ }^{1-4}$. The main source of vitamin D for humans is the exposure to natural sunlight and, therefore, the major cause of vitamin $\mathrm{D}$ deficiency is inadequate sunlight exposure ${ }^{5}$. Therefore, the higher prevalence of vitamin D deficiency in children

\footnotetext{
Correspondence: Teodoro Durá-Travé (tduratra@cfnavarra.es)

'Department of Pediatrics, School of Medicine, University of Navarra,

Pamplona, Spain

${ }^{2}$ Department of Pediatrics, Navarra Hospital Complex, Pamplona, Spain

Full list of author information is available at the end of the article.
}

with obesity might be related to a more sedentary lifestyle and, consequently, a decreased sun exposure.

However, the reason for the association between obesity and lower levels of 25-hydroxy vitamin D $(25(\mathrm{OH}) \mathrm{D})$ and higher parathyroid hormone (PTH) levels is still unclear, and several hypotheses have been proposed about this relationship. The low levels of $25(\mathrm{OH}) \mathrm{D}$ in obesity have been attributed to excessive fat-soluble vitamin deposition in adipose tissue and, consequently, a decreased bioavailability of vitamin $\mathrm{D}^{6}$. On the other hand, secondary elevation of $\mathrm{PTH}$ has been postulated as a predictor of

\section{(c) The Author(s) 2019}

(c) (i) Open Access This article is licensed under a Creative Commons Attribution 4.0 International License, which permits use, sharing, adaptation, distribution and reproduction cc) in any medium or format, as long as you give appropriate credit to the original author(s) and the source, provide a link to the Creative Commons license, and indicate if changes were made. The images or other third party material in this article are included in the article's Creative Commons license, unless indicated otherwise in a credit line to the material. If material is not included in the article's Creative Commons license and your intended use is not permitted by statutory regulation or exceeds the permitted use, you will need to obtain permission directly from the copyright holder. To view a copy of this license, visit http://creativecommons.org/licenses/by/4.0/. 
obesity $^{7}$. PTH might increase calcium influx into adipocytes and thus promote lipogenesis and weight gain ${ }^{8,9}$. Additionally, some studies support that vitamin D increases and PTH decreases after weight loss in both obese adults ${ }^{10}$ and children ${ }^{11}$, suggesting that these changes would be more a consequence than the cause of overweight.

Gender, age, season of the year in which blood is collected and place of residence have also been associated with vitamin D deficiency in healthy school-age children and adolescents ${ }^{2,12,13}$. However, it is unclear whether the same factors could be associated with hypovitaminosis D in children and adolescents with obesity.

Present day society has witnessed a progressive increase in the prevalence of childhood obesity over the last decades. The treatment for this condition is complex and has inconclusive results so far but, after the application of combined strategies, it might turn to be effective ${ }^{14-18}$.

The aim of this study is to analyze the changes in vitamin D status and PTH levels in a group of children with obesity included in a combined dietary-behavioralphysical activity intervention program in order to get BMI status reduction.

\section{Methods}

\section{Participants}

The work presented is a longitudinal study carried out in a sample of 119 patients diagnosed with obesity (59 boys and 60 girls), aged 9.1-13.9 years (median: 11.5 years). All patients included in the study were Caucasian and passed a clinical examination (clinical evaluation was performed every 3 months thereafter) and blood testing before and after the participation in a 1-year intervention program that contains a combination of dietarybehavioral-physical activity. The attention was provided in the Pediatric Endocrinology Unit of the Navarra Hospital Complex (Pamplona, Spain), in the period January 2016-December 2017. They did not receive any additional vitamin D or calcium supplements throughout the combined intervention or previously. Pubertal stage was assigned according to Tanner's criteria in every patient. Children in Tanner stage I were considered prepubertal, and those in Tanner stages II-V were considered pubertal. The place of residence was characterized as urban or rural by means of population (more or less than 10,000 inhabitants, respectively). Overweight individuals were not included in this study.

In addition to that, these parameters (clinical examination and blood testing) were determined in a control group that consisted of 300 healthy Caucasian children (132 boys and 168 girls), aged 8.1-13.9 years (median: 11.2 years), with normal nutritional status: BMI $z$-score ranging from -1.0 (15th percentile) to +1.0 (85th percentile). These participants came from external consultations of the different pediatric subspecialties. There were not any participants suffering from any illness affecting bone health or chronic pathologies that might interfere growth, body composition, food ingestion or physical activity, nor had received any medication (antiepileptic drugs or glucocorticoids) and vitamin D or calcium supplements.

\section{Clinical examination}

The standardized protocol that was used for the anthropometric measurements has been previously published $^{18}$. Anthropometric measurements in patients with obesity were recorded after the first consultation and every 3 months: weight, height, body mass index (BMI) and skinfold thickness (biceps, triceps, sub scapular and suprailiac) and waist circumference.

Weight and height measurements were taken with subjects wearing undergarments and barefoot. Weight was measured using an Año-Sayol scale (reading interval $0-120 \mathrm{~kg}$ and a precision of $100 \mathrm{~g}$ ), and height was measured using a Holtain wall stadiometer (reading interval $60-210 \mathrm{~cm}$, precision $0.1 \mathrm{~cm}$ ). BMI was subsequently calculated by means of the following formula: weight $(\mathrm{kg}) /$ height $^{2}(\mathrm{~m})$.

Skinfold thickness (triceps, biceps, sub scapular, and suprailiac) values were measured with an accuracy of $0.1 \mathrm{~mm}$ on the left side of the body with Holtain skinfold caliper (CMS Weighing Equipment, Crymych, United Kingdom). The body fat percentage (\%) and fat mass $(\mathrm{kg})$ were determined by means of the equations reported by Siri et al., adjusted for sex and age ${ }^{19}$. In the same way, the fat mass index was calculated using the following formula: fat mass $(\mathrm{kg}) /$ height $^{2}(\mathrm{~m})$. Waist circumference was registered using a tape measure placed on a horizontal line equidistant from the last rib and the iliac crest. Measurements were performed by the same trained individual.

The $z$-score values for the BMI and skinfold thickness and waist circumference were calculated applying the program Aplicación Nutricional, from the Spanish Society of pediatric gastroenterology, hepatology and nutrition (Sociedad Española de Gastroenterología, Hepatología y Nutrición Pediátrica, available at http://www.gastroinf.es/ nutritional/). The graphics from Ferrández et al. (Centro Andrea Prader, Zaragoza 2002) were used as reference $\operatorname{charts}^{20}$.

Participants were secondarily diagnosed with obesity when $z$-score values for the BMI were higher than 2.0 (97th percentile).

\section{Blood testing}

Fasting calcium and phosphorus plasma levels were measured by colorimetric methods using a COBAS 8000 analyzer (Roche Diagnostic, Mannheim, Germany). 25 
$(\mathrm{OH}) \mathrm{D}$ levels were calculated by a high-specific chemiluminiscence-immunassay (LIAISON Assay, Diasorin, Dietzenbach, Germany), and PTH levels were determined by a highly specific solid-phase, two-site chemiluminescent enzyme-labeled immunometric assay using an Immulite analyzer (DPC Biermann, Bad Nauheim, Germany).

The criteria for classification of vitamin D status of the United States Endocrine Society were used for categorization. Vitamin D deficiency was then defined when 25 $(\mathrm{OH}) \mathrm{D}$ levels were lower than $20 \mathrm{ng} / \mathrm{ml}(<50 \mathrm{nmol} / \mathrm{L})$, Vitamin D insufficiency when 25(OH)D levels were between 20 and $29 \mathrm{ng} / \mathrm{ml}(50-75 \mathrm{nmol} / \mathrm{L})$ and Vitamin D sufficiency when $25(\mathrm{OH}) \mathrm{D}$ levels reached or surpassed $30 \mathrm{ng} / \mathrm{ml}(>75 \mathrm{nmol} / \mathrm{L})^{21,22}$. Secondary hyperparathyroidism was considered when PTH serum levels were higher than $65 \mathrm{pg} / \mathrm{ml}^{2,7}$.

\section{Combined dietary-behavioral-physical activity intervention}

The combined intervention has been previously explained $^{18}$. The central idea of the program is based on the axiom: "the child becomes skinny keeping a stable weight because he/she is growing" and it included nutritional education, a nutritional intervention, the promotion of physical activity and healthy lifestyles and selfmonitoring on body weight (weekly registration of weight).

All the patients were required to acquire basic practical and theoretical concepts adequate to enable selfmonitoring in order to be included in this study. A multidisciplinary team (nurse, pediatrician and nutritionist) instructed the patients and their families in nutritional education, synchronizing the education and the first visit. The contents of these structured sessions (nutritional value of the different food groups, food pyramid, physical activity, etc.) were customized according to the characteristics of each patient and/or family and continuous guidance was provided to all of them. The program was developed or extended depending on the needs of the patient in subsequent visits.

The approach to maintaining the actual weight is reached by means of a diversified and well-balanced diet for the whole family with no strict restrictions or immediate or exaggerated weight loss. The Mediterranean diet, adapted to family customs or the preferences of the participants, was the model diet. Five daily meals were mandatory, with the condition that meal schedules were respected. The participants were taught to avoid eating in between meals and to increase the time of intake (eating slowly and chewing the food).

In addition, a personalized planning to increase physical activity was suggested to each individual and consisted of a daily, regulated $(60 \mathrm{~min})$ free-choice activity (cycling, swimming, martial arts, walking, etc.) and an increase in daily activity (such as walking, avoiding the use of the elevator, helping in house hold chores, etc.).

A leaflet with general recommendations for their daily diet, physical activity (sports and home activity) and healthy lifestyle was handed to every family.

A good response to treatment (BMI status reduction) was reported when a BMI $z$-score reduction greater than or equal to 0.25 units of the initial value occurred after 12 months of follow up; otherwise, it was considered a failure to treatment ${ }^{23}$.

\section{Statistical analysis}

Results are presented as percentages (\%) and means (M) with the corresponding standard deviations (SD). A posterior statistical analysis (descriptive statistics, Chi-square test and Pearson's correlation, Student's $t$-test or paired $t$ test) was executed using the program Statistical Packages for the Social Sciences version 20.0 (Chicago, IL, USA). Statistical significance was accepted when $P$-value was $<0.05$.

Parents and/or legal guardians were informed and provided consent for the participation in this study in all cases. This study was approved by the Ethics Committee for Human Investigation of our institution (in accordance with the ethical standards laid down in the 1964 Declaration of Helsinki and later amendments).

\section{Results}

Table 1 shows and compares the distribution of the presumed risk factors for hypovitaminosis D between

Table 1 Distribution of presumed risk factors for hypovitaminosis $D$ in obesity and control groups

\begin{tabular}{lccc}
\hline Items & $\begin{array}{l}\text { Obesity group } \\
(\boldsymbol{n}=\mathbf{1 1 9 )}\end{array}$ & $\begin{array}{l}\text { Control group } \\
(\boldsymbol{n}=\mathbf{3 0 0})\end{array}$ & P-value \\
\hline Sex & & & \\
Boys & $59(49.6 \%)$ & $132(44 \%)$ & 0.562 \\
Girls & $60(50.4 \%)$ & $168(56 \%)$ & 0.636 \\
Age group & & $99(33 \%)$ & \\
Childhood & $35(29.4 \%)$ & $201(67 \%)$ & 0.541 \\
Adolescent & $84(70.6 \%)$ & & \\
Season of study & isit & $69(27.6 \%)$ & \\
Winter & $28(23.5 \%)$ & $57(22.8 \%)$ & \\
Spring & $24(20.2 \%)$ & $54(21.6 \%)$ & \\
Summer & $38(31.9 \%)$ & $70(28.0 \%)$ & \\
Autumn & $29(24.4 \%)$ & & \\
Residence & & $181(60.3 \%)$ & \\
Urban & $57(47.9 \%)$ & & \\
Rural & $62(52.1 \%)$ & & \\
\hline
\end{tabular}


obesity and control groups. There were no significant differences in the distribution in relation to sex, age group, season of blood sample collection and place of residence.

Table 2 shows and compares mean values of clinical and biochemical characteristics registered between obesity and control groups before the combined intervention. Weight $z$-score, height $z$-score, BMI $z$-score, body fat percentage, fat mass, fat mass index and waist

Table 2 Clinical and biochemical characteristics in obesity and control groups before combined intervention $(M \pm D S)$

\begin{tabular}{lccc}
\hline Items & $\begin{array}{l}\text { Obesity group } \\
(\boldsymbol{n}=\mathbf{1 1 9})\end{array}$ & $\begin{array}{l}\text { Control group } \\
(\boldsymbol{n}=\mathbf{3 0 0})\end{array}$ & $\begin{array}{l}\boldsymbol{P} \text {-value* } \\
\end{array}$ \\
\hline Age (y) & $11.6 \pm 2.3$ & $11.2 \pm 2.0$ & 0.171 \\
Weight z-score & $3.1 \pm 1.3$ & $-0.2 \pm 0.7$ & 0.001 \\
Height z-score & $0.7 \pm 1.0$ & $0.04 \pm 1.1$ & 0.001 \\
BMl z-score & $3.1 \pm 1.2$ & $-0.06 \pm 0.4$ & 0.001 \\
Percentage body fat (\%) & $37.6 \pm 4.6$ & $24.9 \pm 6.0$ & 0.001 \\
Fat mass (kg) & $26.6 \pm 7.1$ & $9.9 \pm 3.0$ & 0.001 \\
FMI (kg/m²) & $10.8 \pm 1.9$ & $4.7 \pm 0.3$ & 0.001 \\
WC $z$-score & $2.5 \pm 1.2$ & $-0.4 \pm 0.7$ & 0.001 \\
Calcium (mg/dL) & $9.9 \pm 0.3$ & $10.0 \pm 0.3$ & 0.891 \\
Phosphorus (mg/dL) & $4.5 \pm 0.5$ & $4.5 \pm 0.5$ & 0.904 \\
25(OH)D (ng/mL) & $21.9 \pm 8.1$ & $27.9 \pm 7.5$ & 0.001 \\
PTH (pg/mL) & $51.7 \pm 17.0$ & $31.4 \pm 13.8$ & 0.001 \\
\hline
\end{tabular}

*Student's $t$-test

$B M I$ body mass index, FMI fat mass index, PTH parathyroid hormone, WC waist circumference circumference $z$-score were significantly higher in children with obesity $(P<0.05) .25(\mathrm{OH}) \mathrm{D}$ levels were significantly higher in the control group $(P<0.05)$, whereas the mean values for PTH levels were significantly higher in the obesity group $(P<0.05)$. There were no significant differences in age, calcium and phosphorus levels among both groups.

Figure 1 depicts and compares the prevalence of hypovitaminosis D between obesity and control groups before combined intervention. Hypovitaminosis D prevalence was significantly higher in the obesity group (insufficiency: $40.3 \%$ and deficiency: $31.1 \%$ ) than in the control group (insufficiency: $44 \%$ and deficiency: $14 \%$ ). Likewise, the frequency of hyperparathyroidism was significantly higher in the obesity group (20.2\%) than in the control group (4\%).

Table 3 compares the prevalence of each vitamin $D$ status in relation to the presumed risk factors for hypovitaminosis $\mathrm{D}$ in the obesity group. There were no significant differences in relation to sex and age group, but individuals living in an urban environment showed a significantly higher prevalence of vitamin D deficiency compared to those living in rural environment. In addition, the prevalence of vitamin D deficiency was significantly higher in winter, spring and autumn compared to summer.

At baseline, there was statistically significant negative correlation between $25(\mathrm{OH}) \mathrm{D}$ and weight $\mathrm{z}$-score $(r=$ -0.241, $P=0.012)$, BMI $z$-score $(r=-0.272, P=0.005)$, fat mass $(r=-0.271, P=0.007)$, fat mass index $(r=$ $-0.361, P=0.001)$, waist circumference $z$-score $(r=$ $-0.210, P=0.03)$ and PTH $(r=-0.320, P=0.012)$, but no significant correlation to percentage body fat, calcium

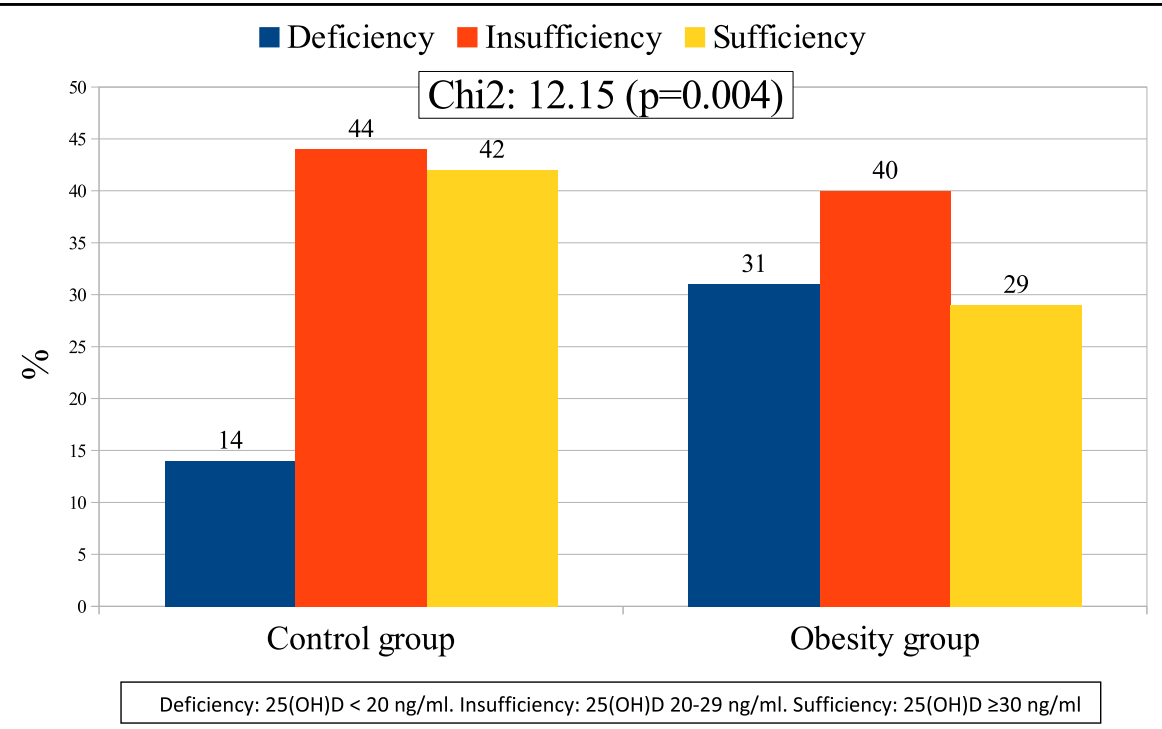

Fig. 1 Vitamin D status in control and obesity groups before combined intervention 
Table 3 Prevalence of vitamin D status according to the presumed risk factors for hypovitaminosis D in patients with obesity

\begin{tabular}{lccc}
\hline Item & Deficiency $\boldsymbol{n}(\%)$ & Insufficiency $\boldsymbol{n}(\%)$ & Sufficiency $\boldsymbol{n}(\%)$ \\
\hline Sex & & & \\
Boys & $14(23.7)$ & $28(47.5)$ & $17(28.8)$ \\
Girls & $23(39.0)$ & $21(35.0)$ & $16(27.1)$ \\
Age group & & & \\
Childhood & $9(25.7)$ & $18(51.4)$ & $8(22.9)$ \\
Adolescent & $28(33.3)$ & $31(36.9)$ & $25(27.8)$ \\
Residence & & $18(31.6)$ & $11(19.3)$ \\
Urban & $28(49.1)$ & $29(46.8)$ & $21(33.9)$ \\
Rural & $12(19.3)$ & $12(42.9)$ & 0.169 \\
Season of study visit & $11(39.3)$ & $10(41.7)$ & $5(17.9)$ \\
Winter & $8(33.3)$ & $12(31.6)$ & $6(25.0)$ \\
Spring & $7(18.4)$ & $14(48.3)$ & $19(50.0)$ \\
Summer & $11(37.9)$ & $4(13.8)$ \\
Autumn & & & 0.010 \\
\hline
\end{tabular}

$x^{2}$ : Chi square test

or phosphorus. There was statistically significant positive correlation between PTH and fat mass $(r=0.293, P=$ $0.004)$, fat mass index $(r=0.341, P=0.001)$, but no significant correlation to weight $z$-score, BMI $z$-score, waist circumference $z$-score, percentage body fat or phosphorus. In addition, there was statistically significant negative correlation between $\mathrm{PTH}$ and calcium $(r=-0.281, P=0.004)$.

A reduction of BMI status in the obesity group between the beginning and the end of the combined intervention (12 months) was observed in 52 patients (43.7\%), and there were no statistically significant differences in relation to sex, age group, season of blood sample and place of residence.

Table 4 shows and compares mean values of anthropometric and biochemical characteristics registered in obesity group with and without reduction of BMI status throughout combined intervention (at the beginning and after 12 months of follow-up). In patients with reduction of BMI status the weight $z$-score, BMI $z$-score, percentage body fat, fat mass index, and waist circumference $z$-score significantly decreased $(P<0.05)$ along the follow-up period. However, in patients without reduction of BMI status, there were no significant differences in weight $z$-score, BMI $z$-score, percentage fat mass, fat mass, fat mass index, and waist circumference $z$-score throughout combined intervention. Throughout combined intervention (at the beginning and after 12 months of follow-up), there were no significant differences in the levels of calcium, phosphorous, 25(OH)D and PTH both in patients with BMI status reduction and in patients without BMI status reduction.

Figure 2 shows and compares the changes of vitamin D status in the obesity group with and without BMI status reduction throughout combined intervention. There are no changes of vitamin D status in patients with BMI status reduction throughout combined intervention. However, in those patients without BMI status reduction throughout combined intervention, there was a significantly increased prevalence $(P<0.05)$ of hypovitaminosis $\mathrm{D}$ along the follow-up period.

\section{Discussion}

Sex, age, season and place of residence have been described as independent factors associated with hypovitaminosis $\mathrm{D}^{1,3,4,7,13,24-26}$; however, in this case, no significant differences were detected in the distribution of these factors among the participants included in this study (obese group and control group). This eventuality will make it possible to compare the results obtained without confounding factors.

In this study, the association between childhood obesity and reduced concentrations of $25(\mathrm{OH}) \mathrm{D}$ is well established ${ }^{6,11,27}$. Nonetheless, we found that $25(\mathrm{OH}) \mathrm{D}$ levels in children with obesity were inversely associated with body fat content, and that this association was stronger than that between $25(\mathrm{OH}) \mathrm{D}$ and BMI or body weight ${ }^{28,29}$. On the other hand, patients with obesity exhibited mean PTH values significantly higher than subjects in normal BMI status, a fact that presumably would allow 
Table 4 Changes in anthropometric and biochemical characteristics in obesity group with and without BMI status reduction throughout combined intervention

\begin{tabular}{|c|c|c|c|c|c|c|}
\hline \multirow[t]{2}{*}{ Items } & \multicolumn{3}{|c|}{$\begin{array}{l}\text { With BMI status reduction } \\
(n=52)\end{array}$} & \multicolumn{3}{|c|}{$\begin{array}{l}\text { Without BMI status reduction } \\
(n=67)\end{array}$} \\
\hline & At baseline & 1 year later & $P$-value* & At baseline & 1 year later & $P$-value ${ }^{*}$ \\
\hline Weight (kg) & $69.9 \pm 13.4$ & $68.4 \pm 13.4$ & 0.529 & $69.7 \pm 14.1$ & $77.3 \pm 16.1$ & 0.035 \\
\hline Weight z-score & $3.3 \pm 1.4$ & $2.5 \pm 1.2$ & 0.005 & $3.2 \pm 1.3$ & $3.4 \pm 1.3$ & 0.588 \\
\hline Height (cm) & $153.4 \pm 11.4$ & $158.6 \pm 9.9$ & 0.019 & $154.3 \pm 11.4$ & $159.8 \pm 12.3$ & 0.062 \\
\hline Height z-score & $0.7 \pm 1.1$ & $0.7 \pm 1.1$ & 0.206 & $0.9 \pm 1.1$ & $0.8 \pm 1.1$ & 0.592 \\
\hline BMl z-score & $3.4 \pm 1.3$ & $2.5 \pm 1.1$ & 0.002 & $3.2 \pm 0.9$ & $3.3 \pm 1.1$ & 0.474 \\
\hline Percentage body fat (\%) & $38.6 \pm 4.6$ & $35.0 \pm 4.1$ & 0.006 & $38.8 \pm 4.7$ & $39.0 \pm 3.9$ & 0.184 \\
\hline Fat mass (kg) & $27.0 \pm 7.1$ & $25.2 \pm 6.4$ & 0.233 & $26.2 \pm 7.4$ & $29.4 \pm 6.8$ & 0.130 \\
\hline $\mathrm{FMI}\left(\mathrm{kg} / \mathrm{m}^{2}\right)$ & $11.1 \pm 2.1$ & $10.0 \pm 2.1$ & 0.022 & $10.9 \pm 2.1$ & $11.3 \pm 1.8$ & 0.386 \\
\hline WC z-score & $2.8 \pm 1.2$ & $2.1 \pm 1.1$ & 0.012 & $2.6 \pm 1.3$ & $2.8 \pm 0.9$ & 0.236 \\
\hline Calcium (mg/dL) & $9.9 \pm 0.3$ & $9.8 \pm 0.2$ & 0.602 & $9.8 \pm 0.2$ & $9.7 \pm 0.3$ & 0.746 \\
\hline Phosphorus (mg/dL) & $4.5 \pm 0.5$ & $4.5 \pm 0.7$ & 0.833 & $4.4 \pm 0.4$ & $4.4 \pm 0.7$ & 0.832 \\
\hline $25(\mathrm{OH}) \mathrm{D}(\mathrm{ng} / \mathrm{mL})$ & $21.8 \pm 8.5$ & $24.6 \pm 7.4$ & 0.192 & $22.8 \pm 6.3$ & $21.5 \pm 6.4$ & 0.138 \\
\hline PTH (pg/mL) & $50.9 \pm 17.3$ & $48.8 \pm 14.9$ & 0.596 & $52.4 \pm 19.3$ & $53.5 \pm 15.7$ & 0.798 \\
\hline
\end{tabular}

*Paired $t$-test

$B M I$ body mass index, FMI fat mass index, PTH parathyroid hormone, WC waist circumference

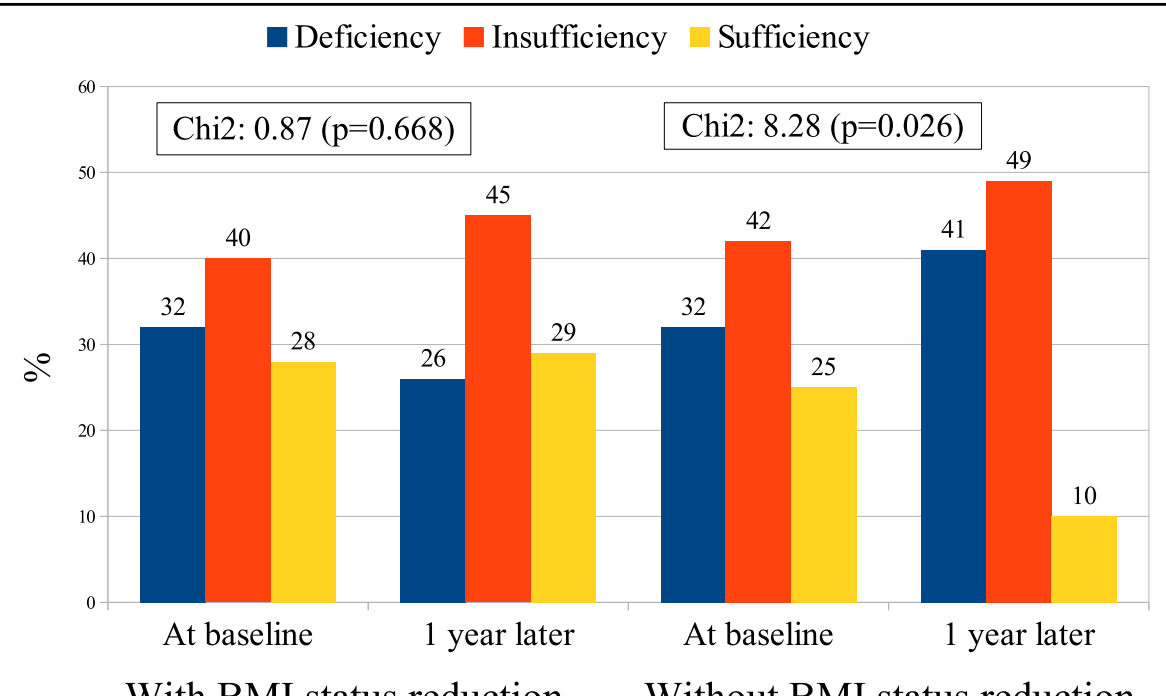

With BMI status reduction Without BMI status reduction

Deficiency: $25(\mathrm{OH}) \mathrm{D}<20 \mathrm{ng} / \mathrm{ml}$. Insufficiency: $25(\mathrm{OH}) \mathrm{D} 20-29 \mathrm{ng} / \mathrm{ml}$. Sufficiency: $25(\mathrm{OH}) \mathrm{D} \geq 30 \mathrm{ng} / \mathrm{ml}$

Fig. 2 Changes of vitamin D status in obesity group with and without BMI status reduction throughout combined intervention

maintaining similar calcium levels in both groups, as we observe in this study. In addition, PTH levels in patients with obesity correlated significantly positively to fat mass, but not significantly to weight or BMI $z$-score.
The low levels of $25(\mathrm{OH}) \mathrm{D}$ in patients with obesity could be attributed to decreased active outdoor life and sun exposure ${ }^{4}$. Clinical studies have verified that obesity does not affect the capacity of the skin to produce vitamin 
$\mathrm{D}$, but could disturb its release from the skin into the circulation. In fact, the increase in blood $25(\mathrm{OH}) \mathrm{D}$ concentrations is significantly smaller in the obese than in non obese subjects after sunlight exposure or orally administered vitamin $\mathrm{D}$, possibly due to the decreased bioavailability because of its excessive deposition or "sequestering" in body fat compartments ${ }^{6}$. Liquid chromatography/mass spectroscopy has shown a positive correlation between vitamin $\mathrm{D}$ in adipose tissue and serum $25(\mathrm{OH}) \mathrm{D}$. This would indicate that adipose tissue would be a storage site for vitamin $\mathrm{D}$ but would not necessarily imply a sequestration ${ }^{30}$. On the other hand, several authors have shown that the levels of bioavailable $25(\mathrm{OH}) \mathrm{D}$ (defined as $25(\mathrm{OH}) \mathrm{D}$ not bound to vitamin $\mathrm{D}$ binding protein) in children with obesity seem similar to children without obesity ${ }^{27}$. According to the freehormone hypothesis, vitamin D-binding protein may act as a serum carrier and reservoir, prolonging the halflife of plasma $25(\mathrm{OH}) \mathrm{D}$ while at the same time regulating its immediate bioavailability to target tissues ${ }^{31}$. Thus, hormonal activity may be reflected by the amounts of bioavailable vitamin, rather than total serum levels.

PTH concentrations were elevated in children with obesity in our study in concordance with most studies ${ }^{2,4,7}$. Hypovitaminosis D implies a lower absorption of dietary calcium. This fact increases PTH secretion (in order to maintain normal levels of serum calcium), and, ultimately, induces osteoclastic activity and, consequently, a loss of bone mineral density ${ }^{5,32}$. Secondary elevation of PTH has been postulated as an independent predictor of obesity. One hypothesis is that this physiologic increase in PTH levels would increase calcium influx into adipocytes, which leads to increased lipogenesis and potentially reduces catecholamine-induced lipolysis as mechanism for increased fat storage ${ }^{8,9,33}$. Nevertheless, some authors have described comparable levels of PTH despite different levels of 25(OH)D in children with and without obesity ${ }^{27}$.

The analysis of the different factors associated to hypovitaminosis D (sex, age group, season of the year and place of residence) suggests that, in children with obesity, age and sex would not be determining variables of body vitamin $\mathrm{D}$ content, but confirms a lower tendency to hypovitaminosis $\mathrm{D}$ in summer time and when the residence is rural. This finding would support the hypothesis that the higher trend to present hypovitaminosis D deficiency in children with obesity would probably be related to a more sedentary lifestyle and, consequently, a decreased sun exposure.

As we observe in this study, 25(OH)D concentrations were negatively related to fat mass status, whereas PTH levels were positively related to it, and this relationship presaged that a decrease in BMI status or fat mass could normalize these hormonal alterations, as previously described in children and adults ${ }^{10,11,34}$. This study has confirmed a significant increase in the prevalence of hypovitaminosis $\mathrm{D}$ in patients with weight or fat mass gain at the end of follow-up with respect to the beginning of the study. However, those individuals who presented with BMI reduction at the end of follow-up showed no difference in the prevalence of hypovitaminosis in comparison with the onset of the study. It is likely that a greater BMI reduction (in fact, at the end of the study they maintain a BMI $z$-score corresponding to obesity) would had resulted in an improvement of the prevalence of hypovitaminosis $\mathrm{D}$.

On another note, we should remark how PTH levels did not change from the onset to the end of the period of follow-up neither in those patients who did not reduce their BMI status nor in those who did. This eventuality suggests that vitamin D biodisponibility is reduced in obese individuals and, consequently, the administration of vitamin D supplements should be considered in these patients in order to avoid the presumably maintained osteoclastic activity induced by $\mathrm{PTH}$, as well as lipogenesis.

In fact, the Endocrine Society recommends the determination of vitamin D in children with obesity and adolescents as individuals at risk of deficiency, and suggests that children with obesity should receive an increased amount of vitamin D (at least two or three times) to satisfy their requirements ${ }^{20,21}$. In addition, hypovitaminosis $\mathrm{D}$ could adversely affect the different non-calcemic functions of vitamin $\mathrm{D}^{5}$.

\section{Conclusions}

This study shows that obesity increase prevalence of suboptimal vitamin D status, and a BMI status reduction in children with obesity could be required to at least stabilize vitamin D status. In these patients, vitamin D status should be regularly controlled and supplementation may be required.

\section{Authors' contributions \\ Contributionship. T.D.T. and F.G.V. participated in study design and data analysis, and wrote the first draft of the manuscript. M.J.C.G., S.B.Z., M.U.M. and L.A.M. participated in data collection and analysis. All authors participated in manuscript preparation and approved its final version.}

\section{Author details \\ ${ }^{1}$ Department of Pediatrics, School of Medicine, University of Navarra, Pamplona, Spain. '2Department of Pediatrics, Navarra Hospital Complex, Pamplona, Spain. ${ }^{3}$ Navarra Institute for Health Research (IdisNA), Pamplona, Spain}

Conflict of interest

The authors declare that they have no conflict of interest.

\section{Publisher's note}

Springer Nature remains neutral with regard to jurisdictional claims in published maps and institutional affiliations. 
Received: 12 June 2018 Revised: 6 March 2019 Accepted: 27 April 2019 Published online: 04 June 2019

\section{References}

1. Turer, C. B., Lin, H. \& Flores, G. Prevalence of vitamin D deficiency among overweight and obese US children. Pediatrics 131, e152-e161 (2013).

2. Vierucci, F. et al. Vitamin D status and predictors of hypovitaminosis D in Italian children and adolescents: a cross-sectional study. Eur. J. Pediatr. 172, 1607-1617 (2013).

3. Bellone, S. et al. Vitamin D levels in a paediatric population of normal weight and obese subjects. J. Endocrinol. Invest 37, 805-809 (2014).

4. Durá-Travé, T., Gallinas-Victoriano, F., Chueca-Guindulain, M. J. \& Berrade-Zubiri, S. Prevalence of hypovitaminosis D and associated factors in obese Spanish children. Nutr. Diabetes 7, e248 (2017).

5. Palermo, N. E. \& Holick, M. F. Vitamin D, bone health, and other health benefits in pediatric patients. J. Pedia. Rehabil. Med 7, 179-192 (2014).

6. Worstman, J., Matsuoka, L. Y., Chen, T. C., Lu, Z. \& Holick, M. F. Decreased bioavailability of vitamin D in obesity. Am. J. Clin. Nutr. 72, 690-693 (2000).

7. Weng, F. L., Shults, J., Leonard, M. B., Stallings, V. A. \& Zemel, B. S. Risk factors for low serum 25-hydroxyvitamin D concentrations in otherwise healthy children and adolescents. Am. J. Clin. Nutr. 86, 150-158 (2007).

8. Zemel, M. B., Shi, H., Greer, B., Dirienzo, D. \& Zemel, P. C. Regulation of adiposity by dietary calcium. FASEB J. 14, 1132-1138 (2000).

9. McCarty, M. F. \& Thomas, C. A. PTH excess may promote weight gain by impeding catecholamine-induced lipolysis -implications for the impact of calcium, vitamin D, and alcohol on body weight. Med. Hypotheses $\mathbf{6 1 , 5 3 5 - 5 4 2}$ (2003).

10. Jensen, L. B., Kollerup, G., Quaade, F. \& Sorensen, O. H. Bone minerals changes in obese women during a moderate weight loss with and without calcium supplementation. J. Bone Miner. Res. 16, 141-147 (2001).

11. Reinehr, T., de Sousa, G., Alexy, U., Kersting, M. \& Andler, W. Vitamin D status and parathyroid hormone in obese children before and after weight loss. Eur. J. Endocrinol. 157, 225-232 (2007).

12. Karagüzel, $G$. et al. Seasonal vitamin D status of healthy schoolchildren and predictors of low vitamin D status. J. Pedia. Gastroenterol. Nutr. 58, 654-660 (2014).

13. Durá-Travé, T. \& Gallinas-Victoriano, F. Dietary pattern among schoolchildren with normal nutritional status in Navarre, Spain. Nutrients 6 1475-1487 (2014).

14. Nemet, D. et al. Short and long-term beneficial effects of a combined dietary-behavioral-physical activity intervention for the treatment of childhood obesity. Pediatrics 115, e443-449 (2005).

15. Kriemler, S. et al. Effect of school based physical activity programme (KISS) on fitness and adiposity in primary schoolchildren: cluster randomised controlled trial. BMJ 340, c785 (2010).
16. De Miguel-Etayo, P. et al. Body composition changes during interventions to treat overweight and obesity in children and adolescents; a descriptive review. Nutr. Hosp. 28, 52-62 (2013)

17. Styne, D. M. et al. Pediatric obesity-assessment, treatment, and prevention: an Endocrine Society Clinical Practice Guideline. J. Clin. Endocrinol. Metab. 102, 1-49 (2017).

18. Durá-Travé, T. et al. Assessment of body composition changes during a combined intervention for the treatment of childhood obesity. Nutrition 59, 116-120 (2019).

19. Siri, W. E. Body composition from fluid spaces and density: analysis of methods. Nutrition 9, 480-491 (1993).

20. Ferrández, A. et al. Longitudinal pubertad growth ac]ording to age at pubertal study of normal Spanish children from birth to adulthood (anthoprometric, pubertal, radiological and intellectual data). Pedia. Endocr. Rev. 2, 423-559 (2005).

21. Holick, M. F. et al. Endocrine Society. Evaluation, treatment, and prevention of vitamin D deficiency: an Endocrine Society clinical practice guideline. J. Clin. Endocrinol. Metab. 96, 1911-1930 (2011).

22. Holick, M. F., Binkley, N. C. \& Bischoff-Ferrari, H. A. Guidelines for preventing and treating vitamin $D$ deficiency and insufficiency revisited. J. Clin. Endocrinol. Metab. 97, 1153-1158 (2012).

23. Ford, A. L., Hunt, L. P., Cooper, A. \& Shield, J. P. What reduction in BMI SDS is required in obese adolescents to improve body composition and cardiometabolic health? Arch. Dis. Child 95, 256-61 (2010).

24. Alemzadeh, R., Kichler, J., Babar, G. \& Calhoun, M. Hypovitaminosis D in obese children and adolescents: relationship with adiposity, insulin sensitivity, ethnicity, and season. Metabolism 57, 183-191 (2008).

25. Pacífico, L. et al. Low 25(OH)D3 levels are associated with total adiposity metabolic syndrome, and hypertension in Caucasian children and adolescents. Eur. J. Endocrinol. 165, 603-611 (2011).

26. Vierucci, F., Del Pistoia, M., Fanos, M., Erba, P. \& Saggese, G. Prevalence of hypovitaminosis $D$ and predictors of vitamin D status in Italian healthy adolescents. Ital. J. Pedia. 40, 54 (2014).

27. Miraglia del Giudice, E. et al. Bioavailable vitamin D in obese children: the role of insulin resistance. J. Clin. Endocrinol. Metab. 100, 3949-3955 (2015).

28. Arunabh, S., Pollack, S., Yeh, J. \& Aloia, J. F. Body fat content and 25hydroxyvitamin D levels in healthy women. J. Clin. Endocrinol. Metab. 88, 157-161 (2003).

29. Vanlint, S. Vitamin D and obesity. Nutrients 5, 949-956 (2013).

30. Blum, M. et al. Vitamin D3 in fat tissue. Endocrine 33, 90-94 (2008),

31. Chun, R. F. et al. Vitamin D and DBP: The free hormone hypothesis revisited. J. Steroid Biochem Mol. Biol. 144A, 132-137 (2014).

32. Holick, M. F. Vitamin D deficiency. N. Engl. J. Med 357, 266-281 (2007).

33. Smotkin-Tangorra, M. et al. Prevalence of vitamin D insufficiency in obese children and adolescents. J. Pedia. Endocrinol. Metab. 20, 817-823 (2007).

34. Rock, C. L. et al. Weight loss is associated with increased serum 25hydroxyvitamin D in overweight or obese women. Obesity 20, 2296-2301 (2012). 